Check for updates

Cite this: RSC Adv., 2019, 9, 16313

Received 13th February 2019

Accepted 17th May 2019

DOI: 10.1039/c9ra01120j

rsc.li/rsc-advances

\section{Flexible quasi-solid-state zinc ion batteries enabled by highly conductive carrageenan bio-polymer electrolyte $\uparrow$}

\author{
Yuan Huang,,$_{+}^{\mathrm{a}}$ Jiuwei Liu,,$^{\mathrm{a}}$ Jiyan Zhang, ${ }^{\mathrm{a}}$ Shunyu Jin, ${ }^{\mathrm{b}}$ Yixiang Jiang, ${ }^{\mathrm{c}}$ \\ Shengdong Zhang, ${ }^{a}$ Zigang Li, (DD ${ }^{c}$ Chunyi Zhi, (DD d Guoging Du and Hang Zhou (DD *a
}

Flexible $\mathrm{Zn}-\mathrm{MnO}_{2}$ batteries as wearable electronic power source have attracted much attention in recent years due to their low cost and high safety. To promote the practical application of flexible $\mathrm{Zn}-\mathrm{MnO}_{2}$ batteries, it is imperative to develop flexible, mechanically robust and high performance solid state electrolyte. Herein, we construct a rechargeable quasi-solid-state zinc ion battery using kappa-carrageenan bio-polymer electrolyte. The kappa-carrageenan electrolyte is eco-friendly, low cost, and highly conductive (3.32 $\times 10^{-2} \mathrm{~S} \mathrm{~cm}^{-1}$ at room temperature). The mechanical robustness of kappa-carrageenan electrolyte is further reinforced by using a rice paper as scaffold. Benefiting from high ionic conductivity of the biopolymer electrolyte, our zinc ion battery delivers a significant high energy density and power density (400 W h kg $\mathrm{Wh}^{-1}$ and $7.9 \mathrm{~kW} \mathrm{~kg}^{-1}$, respectively), high specific capacity $\left(291.5 \mathrm{~mA} \mathrm{~h} \mathrm{~g}^{-1}\right.$ at $0.15 \mathrm{~A} \mathrm{~g}^{-1}$ ), fast charging and discharging capability (120.0 $\mathrm{mA} \mathrm{h} \mathrm{g}^{-1}$ at $6.0 \mathrm{~A} \mathrm{~g}^{-1}$ ). The zinc ion battery with bio-polymer electrolyte also shows excellent cycling stability and high bending durability. This work brings new research opportunities in developing low-cost flexible solid-state zinc ion batteries using green natural polymer.

\section{Introduction}

In recent years, the rapid development of flexible electronics has triggered a huge research demand on flexible power sources. A lot of important work on flexible-based energy storage devices has been reported. ${ }^{1-4}$ As the flexible or wearable electronics are usually closely attached to human body, one would expect the flexible batteries to have higher safety and environmental standards than other batteries. In this regard, aqueous electrolyte based zinc ion batteries (ZIBs) have drawn a lot of interest not only because they are highly reliable and environmentally friendly, but also because of the abundance of the raw materials, such as $\mathrm{Zn}$ sources. ${ }^{5-12}$ Conventionally, neutral or mildly acidic sulfate salt aqueous solutions such as $\mathbf{Z n S O}_{4}$ solution are employed in ZIBs as their electrolytes. Compared to

${ }^{a}$ School of Electronic and Computer Engineering, Peking University Shenzhen Graduate School, Shenzhen 518055, PR China. E-mail: zhouh81@pkusz.edu.cn

${ }^{b}$ Center for Micro- and Nanoscale Research and Fabrication, University of Science and Technology of China, Hefei, PR China

'State Key Laboratory of Chemical Oncogenomics, School of Chemical Biology \& Biotechnology, Peking University Shenzhen Graduate School, Shenzhen 518055, Guangdong, China

${ }^{d}$ Department of Materials Science and Engineering, City University of Hong Kong, 83 Tat Chee Avenue, Kowloon, Hong Kong 999077, China

'Zinergy Shenzhen Limited, Taohuayuan Science Park, Shenzhen 518101, China

$\dagger$ Electronic supplementary information (ESI) available. See DOI: 10.1039/c9ra01120j

¥ Yuan Huang and Jiuwei Liu contributed equally to this work. other salts, the sulfate salt solution provides higher ionic conductivity and larger electrochemically stable window. ${ }^{13}$ More importantly, the recharge ability of aqueous $\mathrm{Zn}-\mathrm{MnO}_{2}$ batteries can be significantly improved by optimizing the amount of $\mathrm{MnSO}_{4}$ salt in the $\mathrm{ZnSO}_{4}$ aqueous electrolyte. ${ }^{14}$ Nonetheless, aqueous based electrolyte in the battery of this kind is likely to leak under mechanical stress such as bending or stretching, leading to degradation or failure of the batteries. To further promote the ZIBs for wearable or flexible electronics application, it is very critical to develop exclusive ZIBs solid-state electrolytes which can avoid electrolyte leakage while maintaining high flexibility.

So far, several types of zinc ion conducting polymer electrolytes have been invented, such as electrolytes based on $\mathrm{ZnCl}_{2}$ / polyvinyl-alcohol (PVA) gel-like electrolyte, and $\mathrm{ZnTf}_{2}$ in combination with poly(vinilydenefluoride-co-hexafluoropropylene). ${ }^{\mathbf{1 5}, 16}$ Nonetheless, the ZIBs based on the former $\mathrm{ZnCl}_{2}$ /PVA electrolyte showed very narrow voltage plateaus, ${ }^{13}$ while the later one, $\mathrm{ZnTf}_{2}$ based electrolyte, suffers from low ionic conductivity $\left(3.82 \times 10^{-3} \mathrm{~S} \mathrm{~cm}^{-1}\right) .{ }^{16}$ It is only until recently that high conductive zinc ion solid-state electrolyte for wearable ZIBs has been reported. Examples include a gelatin and PAM based hierarchical polymer electrolyte ${ }^{17}$ and $\mathrm{ZnSO}_{4} / \mathrm{MnSO}_{4} /$ xanthan gum electrolyte, ${ }^{13}$ which exhibit high ionic conductivities of $1.76 \times 10^{-2}$ and $1.46 \times 10^{-2} \mathrm{~S} \mathrm{~cm}^{-1}$, respectively. Inspired by the above previous works, in an attempt to further minimize the manufacturing cost and environmental impact, we initialize an investigation on bio-degradable solid-state 
electrolytes with high zinc ion conductivity, and with easy fabrication process.

Herein, we utilize kappa-carrageenan, a natural polymer which has been widely used in biomedical and food application, ${ }^{18}$ to form solid-state $\mathrm{ZnSO}_{4} / \mathrm{MnSO}_{4}$ electrolyte and achieve highly flexible ZIBs with $\mathrm{MnO}_{2}$-based hybrid cathodes. The structure of kappa-carrageenan (Fig. 1a), with formula of $\mathrm{C}_{24} \mathrm{H}_{36} \mathrm{O}_{25} \mathrm{~S}_{2}{ }^{-2}$, is consist of alternating 3-linked $\beta$-D-galactose-4sulfate and 4-linked 6-anhydro- $\alpha$-galactopyranose having one negative charge per disaccharide repeating unit. ${ }^{19}$ The structure of kappa-carrageenan consists of hydroxyl groups, which enables the formation of coordinate bonds with cations. It is abundant in nature, non-toxic, renewable, biocompatible, and cost effective compared to synthetic polymers. ${ }^{20} \mathrm{~A}$ few works have been reported in literature to make polymer electrolytes using kappa-carrageenan, such as biopolymer electrolytes based on carboxymethyl kappa-carrageenan and ionic liquid 1butyl-3-methylimidazolium chloride, ${ }^{21}$ biopolymer blend based on kappa-carrageenan and cellulose derivatives, ${ }^{22}$ which exhibit ionic conductivities of $5.76 \pm 0.20 \times 10^{-3}$ and $3.25 \times$ $10^{-4} \mathrm{~S} \mathrm{~cm}^{-1}$, respectively. Moreover, kappa-carrageenan also has been used as electrolyte for energy storage devices (e.g. supercapacitors, ${ }^{23,24}$ and $\mathrm{Al} /$ air batteries ${ }^{25}$ ), where they achieve solid-state electrolyte with mechanical stability or high values of ionic conductivities. In the present work, the preparation of the bio-polymer electrolyte was completed by dissolving kappacarrageenan in aqueous $\mathrm{ZnSO}_{4} / \mathrm{MnSO}_{4}$ solution, and filled the solution in the network of rice paper. The biopolymer electrolyte with rice paper is denoted as KCR electrolyte. The rice paper is adopted to effectively reduce the chances of short circuit as well as improve the mechanical robustness of solid-state electrolyte. The KCR electrolyte fabrication process is simple and efficient. It does not need water and oxygen-free environment or other protection measures, which is ideal for scaling up production. The KCR electrolyte maintains remarkable flexibility and exhibits an ultra-high ionic conductivity of $3.32 \times$ $10^{-2} \mathrm{~S} \mathrm{~cm}^{-1}$ at room temperature, one of the best record reported so far for ZIBs solid-state electrolyte. The ZIBs with KCR demonstrates a high specific capacity of $291.5 \mathrm{~mA} \mathrm{~h} \mathrm{~g}^{-1}$ at $0.15 \mathrm{~A} \mathrm{~g} \mathrm{~g}^{-1}$, fast charging and discharging capability (120.0 $\mathrm{mA} \mathrm{h} \mathrm{g}^{-1}$ at $\left.6.0 \mathrm{~A} \mathrm{~g}^{-1}\right)$, good cycling stability, and high reliability bearing cycles of bending.

\section{Experimental}

\subsection{Preparation of KCR electrolyte, cathode and anode}

$1 \mathrm{~g}$ pristine kappa-carrageenan (Aladdin) was added into $5 \mathrm{~mL}$ the mixture solution of $2 \mathrm{~mol} \mathrm{~L}^{-1} \mathrm{ZnSO}_{4}$ (AR grade, Mcaklin) and $0.1 \mathrm{~mol} \mathrm{~L}^{-1} \mathrm{MnSO}_{4}$ (AR grade, Mcaklin), followed by intensive stirring at room temperature until the kappacarrageenan was dissolved. After that, rice paper was immersed into the mixture. Kappa-carrageenan based hydrogel was formed in the rice paper pores after solidification, and a KCR film with good flexibility was obtained.

The $\mathrm{MnO}_{2}$ nanosheets were synthesized by a hydrothermal method and the $\mathrm{MnO}_{2} /$ reduced graphene oxide $\left(\mathrm{MnO}_{2} / \mathrm{rGO}\right)$ electrodes were prepared using a vacuum filtration method. ${ }^{26}$ $\mathrm{Zn}$ was deposited on carbon cloth by an electrodeposition method. ${ }^{15}$ The mass loading of $\mathrm{MnO}_{2}$ is $3 \mathrm{mg} \mathrm{cm}{ }^{-2}$. The mass loading of the cathode (including $\mathrm{MnO}_{2}, \mathrm{rGO}$, and carbon cloth)

(a)
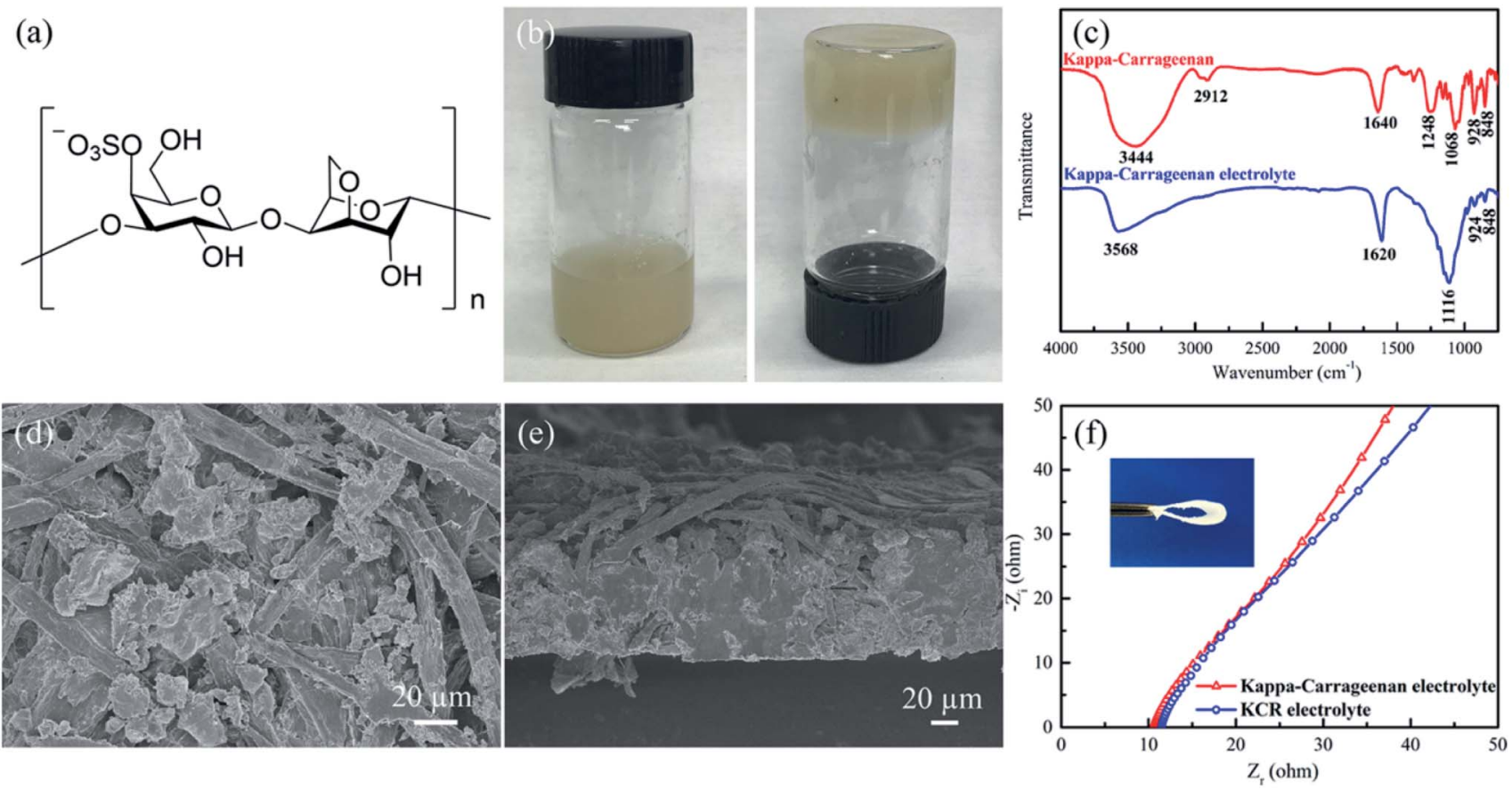

Fig. 1 (a) The molecular formula of kappa-carrageenan. (b) Photograph of kappa-carrageenan electrolyte after adding $2 \mathrm{M}_{\mathrm{ZnSO}} \mathrm{and}_{0.1} \mathrm{M}$ $\mathrm{MnSO}_{4}$ aqueous solutions. (c) FTIR spectra of pure kappa-carrageenan polymer and $\mathrm{ZnSO}_{4} / \mathrm{MnSO}_{4}$ added kappa-carrageenan electrolyte. (d) SEM image of KCR electrolyte. (e) The cross-sectional SEM image of KCR electrolyte. (f) AC impedance spectra of the kappa-carrageenan electrolyte without rice paper and the KCR electrolyte. Inset in (f): photograph of a folded KCR electrolyte sample. 
is $17.75 \mathrm{mg} \mathrm{cm}{ }^{-2}$. The mass loading of the anode (including electroplated $\mathrm{Zn}$ and carbon cloth) is $23.51 \mathrm{mg} \mathrm{cm}^{-2}$.

\subsection{Structure and morphology characterization}

The morphologies were characterized by a field-emission scanning electron microscope (FESEM, Zeiss SUPRA-55). Transmission electron microscopy (TEM) measurements were also carried out with a Tecnai F20 (FEI) microscope operating at $200 \mathrm{kV}$. The crystallinity and phases of the samples were examined by X-ray diffraction (XRD, D8 Advance). FTIR spectra of samples were performed with a Bruker Vertex 70 Fourier transform infrared spectrometer.

\subsection{Electrochemical characterization}

The electrochemical properties of KCR electrolyte were characterized by using $\mathrm{MnO}_{2} / \mathrm{rGO}$ electrode as cathode and electroplated $\mathrm{Zn}$ on carbon cloth as anode. Cyclic voltammetry was conducted at a scanning rate of $0.2 \mathrm{mV} \mathrm{s}^{-1}$ between 1.0 and $1.9 \mathrm{~V}$ vs. $\mathrm{Zn}^{2+} / \mathrm{Zn}$ (CHI660, Shanghai CH Instrument Co., Ltd.). Galvanostatic charging/discharging cycles were tested at different current density on a multichannel battery test system (CT2001A, Wuhan Kingnuo Electronic Co., Ltd.). The ionic conductivity of KCR electrolyte was characterized by placing a piece of KCR electrolyte between two stainless sheets. Impedance measurements were carried out between $10 \mathrm{kHz}$ to $0.01 \mathrm{~Hz}$ with an AC amplitude of $5 \mathrm{mV}$ (CHI 660C, Shanghai $\mathrm{CH}$ Instrument Co., Ltd.). The equation of ionic conductivity can be expressed as $\sigma=l / R A$, where $\sigma$ is conductivity, and $l, R$, and $A$ represent the thickness of the KCR electrolyte, the bulk resistance (the real impedances at the highest frequency), and the

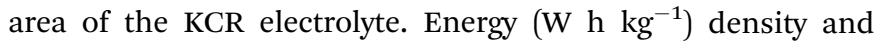
power density $\left(\mathrm{W} \mathrm{kg}^{-1}\right.$ ) were calculated by using the following equations

$$
\begin{gathered}
E=\int U I \mathrm{~d} t / m \\
P=E / t
\end{gathered}
$$

where $I$ is the discharging current, $U$ is the cell voltage, $\mathrm{d} t$ is the time differential, $m$ is the mass of the $\mathrm{MnO}_{2}$, and $t$ is the discharging time.

\section{Results and discussion}

Fig. $1 \mathrm{~b}$ shows the photographs of the kappa-carrageenan after adding $\quad \mathrm{ZnSO}_{4} / \mathrm{MnSO}_{4}$ aqueous solution. The kappacarrageenan electrolyte appears to be a very stable and uniform gel electrolyte. The Fourier-transform infrared spectroscopy (FTIR) spectra of the pure kappa-carrageenan polymer and the kappa-carrageenan electrolyte are shown in Fig. 1c. The red line in Fig. 1c represents the basic characteristics of kappacarrageenan. As reported previously, the band around $3444 \mathrm{~cm}^{-1}, 2912 \mathrm{~cm}^{-1}$, and $1640 \mathrm{~cm}^{-1}$ were related to $\mathrm{O}-\mathrm{H}$ stretch, $\mathrm{C}-\mathrm{H}$ stretch, and asymmetric vibration of $-\mathrm{COO}^{-} .{ }^{27}$ The typical band around $1248 \mathrm{~cm}^{-1}$, and $1068 \mathrm{~cm}^{-1}$, and $848 \mathrm{~cm}^{-1}$ corresponds to $\mathrm{O}=\mathrm{S}=\mathrm{O}$ symmetric vibration, $\mathrm{C}-\mathrm{O}$ stretching, and $\mathrm{C}_{4}-\mathrm{O}-\mathrm{S}$ stretching vibration. ${ }^{27}$ The band near $928 \mathrm{~cm}^{-1}$ proved the existence of $\mathrm{C}-\mathrm{O}-\mathrm{C}$ of 3,6-anhydro-D-galactose. ${ }^{27}$ Compared with FTIR spectrum of the kappa-carrageenan, the intensity of the peak around $1116 \mathrm{~cm}^{-1}$ in the FTIR spectrum of the kappa-carrageenan electrolyte becomes dominant, which is directly related to the existence of $\mathrm{SO}_{4}{ }^{2-}{ }^{13}$

Pure kappa-carrageenan electrolyte film can be deposited by a simple casting method. However, the as-deposited film is fragile. In order to improve the mechanical strength and flexibility, a Chinese painting rice paper was introduced as a flexible scaffold during fabrication to complete the flexible KCR electrolyte. The rice paper is well known for its excellent wettability, tensile strength and high flexibility. Fig. S1a $\dagger$ shows the scanning electron microscope (SEM) image of the rice paper used in this work. The rice paper is comprised of randomly crosslinked fibers with an average diameter of $\sim 10 \mu \mathrm{m}$, and a thickness of $\sim 50 \mu \mathrm{m}$ measured from the cross-sectional SEM image (Fig. S1b†). By immersing the rice paper into the kappacarrageenan electrolyte, a final solid-state KCR electrolyte film with thickness of $\sim 100 \mu \mathrm{m}$ thick was obtained, as shown in Fig. 1d and e.

Sufficient flexibility is essential for the application of solidstate electrolytes in flexible ZIBs. The KCR demonstrates excellent flexibility and can be repeatedly bent (inset in Fig. 1f). The ionic conductivity of KCR films was obtained from the AC impedance spectra (Fig. 1f). It exhibits a high ionic conductivity of $3.32 \times 10^{-2} \mathrm{~S} \mathrm{~cm}^{-1}$ at room temperature. Compared with other zinc ion conducting polymer electrolytes in literature, the KCR electrolyte shows the highest conductivity to the best of our knowledge (Table S1†). It is worth noting the rice paper in KCR has no contribution to the ionic conductivity of KCR film. The remarkable flexibility together with high ionic conductivity empowers the KCR to be an ideal electrolyte for flexible solidstate ZIBs.

Solid-state ZIBs are then assembled in an open-air environment using $\mathrm{MnO}_{2} / \mathrm{rGO}$ composite cathode, electroplated zinc anode, and the KCR electrolyte (Fig. S2a †). In this work, $\alpha-\mathrm{MnO}_{2}$ nanosheets were synthesized by a hydrothermal method. ${ }^{26}$ The SEM image (Fig. S2b $\dagger$ ) and the TEM image (Fig. S2c $\dagger$ ) discloses the nanosheet structure and crumpled surface of $\alpha-\mathrm{MnO}_{2}$, respectively. In Fig. $\mathrm{S} 3 \dagger$, all Bragg peaks in X-ray powder diffraction (XRD) pattern of the $\mathrm{MnO}_{2}$ can be indexed to the crystalline phase of $\alpha-\mathrm{MnO}_{2}$ (JCPDS: 44-0141). A flexible $\mathrm{MnO}_{2} /$ rGO composite electrode and electroplated $\mathrm{Zn}$ on carbon cloth were used as cathode and anode, respectively. ${ }^{26}$ The XRD patterns of the crystalline phases of electroplated zinc are presented in Fig. S4, $\dagger$ where all the diffraction peaks of electroplated zinc are well-indexed to the characteristic peaks of zinc (JCPDS: 4-831). The freestanding $\mathrm{Zn}$ nanosheets homogeneously grown on the carbon fiber are disclosed in the SEM image of Fig. S2d. $\dagger$

Fig. 2a plots the cyclic voltammogram of solid-state ZIBs with KCR electrolyte. The reversible redox peaks (reduction peaks: 1.238 and $1.364 \mathrm{~V}$, oxidation peak: $1.584 \mathrm{~V}$ ) can be clearly observed. The charging and discharging profiles of the samples 

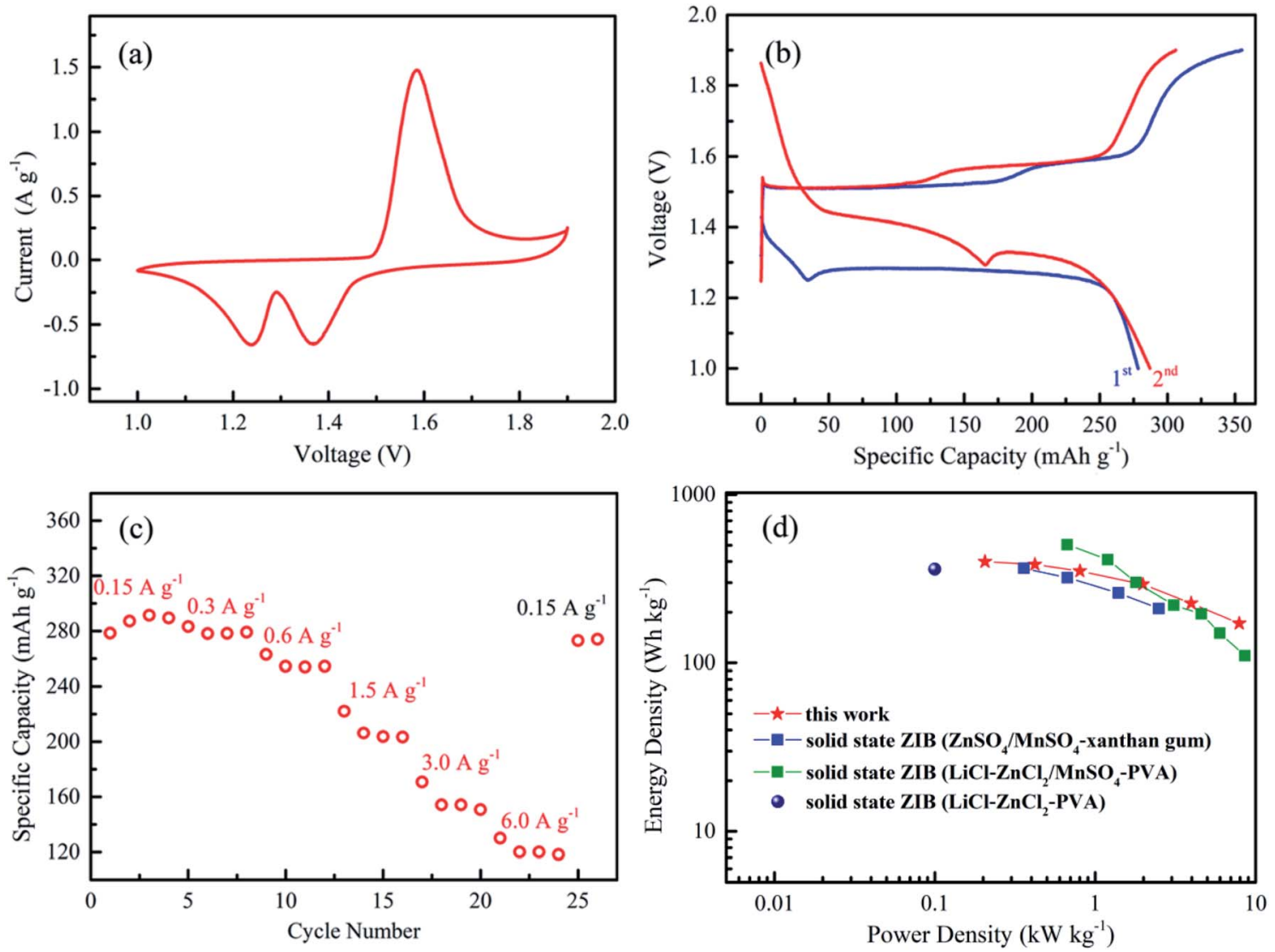

Fig. 2 (a) Cyclic voltammogram of the solid-state ZIBs with KCR electrolyte. (b) The charging/discharging profiles of the first and second cycles at the current density of $0.15 \mathrm{~A} \mathrm{~g}^{-1}$. (c) Specific capacities of the solid-state ZIBs at various current densities. (d) Ragone plots of the solid-state ZIBs with KCR electrolyte. The values reported from other solid-state ZIBs are included for comparison. ${ }^{33,15,29}$

at the first two cycles are shown in Fig. 2b, which presents two discharge plateaus mainly due to the subsequent $\mathrm{H}^{+}$and $\mathrm{Zn}^{2+}$ insertion/extraction process during the discharging/charging. ${ }^{28}$ The fabricated ZIBs deliver capacities of 278.5 and $287.1 \mathrm{~mA} \mathrm{~h} \mathrm{~g}^{-1}$ at $0.15 \mathrm{~A} \mathrm{~g}^{-1}$ in the initial two cycles. Fig. $2 \mathrm{c}$ shows the rate performance of solid state ZIBs. The battery can deliver discharging capacity of $\sim 291.5 \mathrm{~mA} \mathrm{~h} \mathrm{~g}^{-1}$ at $0.15 \mathrm{~A} \mathrm{~g}^{-1}$. Impressively, ZIBs with KCR electrolyte achieve a high discharge capability of $120.0 \mathrm{~mA} \mathrm{~h} \mathrm{~g}{ }^{-1}$ at a high current density of $6.0 \mathrm{~A} \mathrm{~g}^{-1}$. The discharge time is limited to only $72 \mathrm{~s}$. These results indicate a good rate capability and ultrafast chargedischarge ability of ZIBs with KCR electrolyte. Such rate performance of our ZIBs with KCR electrolyte outperforms most of the reported $\mathrm{ZIBs}\left(\mathrm{Zn}-\mathrm{MnO}_{2}\right)$ with other solid-state electrolytes (Table $\mathrm{S} 2 \dagger$ ), such as $\mathrm{Zn}-\mathrm{MnO}_{2}$ battery with PVA electrolyte $\left(76 \mathrm{~mA} \mathrm{~h} \mathrm{~g}{ }^{-1}\right.$ at $\left.5.58 \mathrm{~A} \mathrm{~g}^{-1}\right),{ }^{15} \mathrm{Zn}-\mathrm{MnO}_{2}$ battery with xanthan gum (120-150 $\mathrm{mA} \mathrm{h} \mathrm{g}^{-1}$ at $\left.3.08 \mathrm{~A} \mathrm{~g}^{-1}\right)^{13}$ and $\mathrm{Zn}-\mathrm{MnO}_{2}$ battery with gelatin and polyacrylamide based hierarchical polymer electrolyte $\left(150 \mathrm{~mA} \mathrm{~h} \mathrm{~g}{ }^{-1}\right.$ at $\left.1.848 \mathrm{~A} \mathrm{~g}^{-1}\right) \cdot{ }^{17}$ When cycling back to $0.15 \mathrm{~A} \mathrm{~g}^{-1}$, a discharge capacity of $273.0 \mathrm{~mA} \mathrm{~h} \mathrm{~g}{ }^{-1}$ is recovered. This superior rate performance can be attributed to the following factors: (1) the KCR electrolyte exhibits an ultra-high ionic conductivity, which improves the rate performance of ZIBs; (2) the presence of rGO in the cathode effectively enhances the charge transport (Fig. $\mathrm{S} 5 \dagger$ ).
The energy and power densities of our battery (based on the mass of $\mathrm{MnO}_{2}$ ) with KCR electrolyte are shown in Fig. 2d and

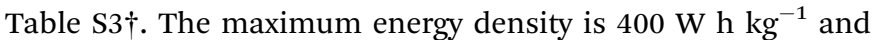
peak power density is $7.9 \mathrm{~kW} \mathrm{~kg}^{-1}$, both of which are higher than previous reported values from flexible ZIBs with xanthan gum and PVA electrolyte ( $\mathrm{LiCl}-\mathrm{ZnCl}_{2}-\mathrm{PVA}$ ) based $\mathrm{Zn}-\mathrm{MnO}_{2}$ battery ${ }^{13,29}$ At high current rates, the energy density of ZIBs with KCR electrolyte are higher than that of the PVA electrolyte (LiCl$\mathrm{ZnCl}_{2} / \mathrm{MnSO}_{4}-\mathrm{PVA}$ ) based $\mathrm{Zn}-\mathrm{MnO}_{2}$ battery, ${ }^{15}$ while the power densities are comparable $\left(171 \mathrm{~W} \mathrm{~h} \mathrm{~kg}^{-1} / 7.9 \mathrm{~kW} \mathrm{~kg}^{-1}\right.$ (for ZIBs with KCR electrolyte) vs. $110 \mathrm{~W} \mathrm{~h} \mathrm{~kg} \mathrm{~g}^{-1} / 8.6 \mathrm{~kW} \mathrm{~kg}^{-1}$ (for ZIBs with PVA electrolyte)). Taking the total mass of the cell (including $\mathrm{MnO}_{2}, \mathrm{rGO}$, electroplated $\mathrm{Zn}$ and current collectors (carbon cloth)) into consideration, the gravimetric energy density of battery is $29.1 \mathrm{~W} \mathrm{~h} \mathrm{~kg}^{-1}$.

The cycling performance of the solid-state ZIBs with KCR electrolyte is then tested at high rates $\left(6.0 \mathrm{~A} \mathrm{~g}^{-1}\right)$. As shown in Fig. 3a, $80 \%$ of its initial capacity still remained even the cyclic number extended to 450 cycles at $6.0 \mathrm{~A} \mathrm{~g}^{-1}$, indicating the excellent cycling stability of the solid-state ZIBs with KCR electrolyte. The morphological characterization of the cathode and anode was carried out after 450 cycles. As shown in Fig. 3b, the SEM image of the $\mathrm{MnO}_{2}$ after cycling test demonstrates a nanosheet structure similar to that before the test. In addition, the freestanding $\mathrm{Zn}$ nanosheets can be observed in the 

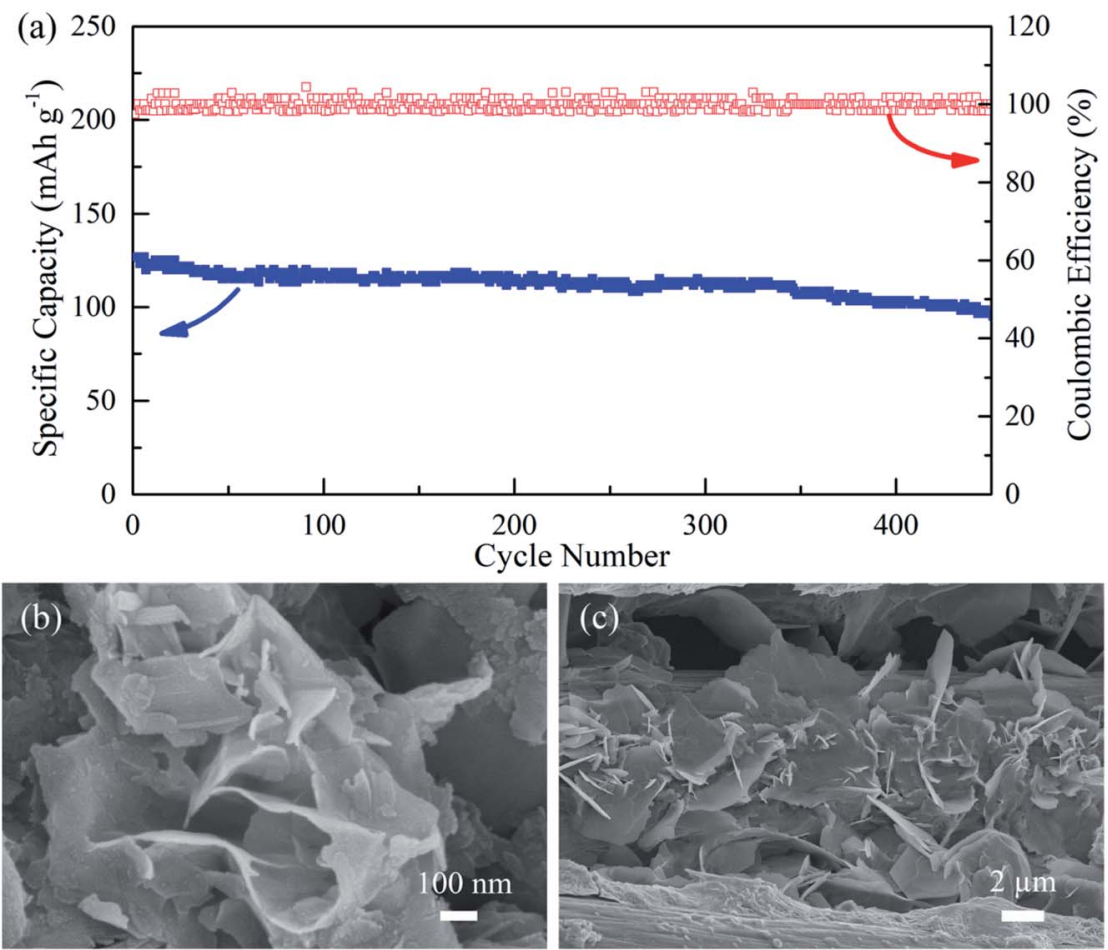

Fig. 3 (a) Cycling stability of the solid-state ZIBs with KCR electrolyte cycled at $6.0 \mathrm{~A} \mathrm{~g}^{-1}$ and corresponding coulombic efficiency. SEM images of (b) the $\mathrm{MnO}_{2}$ cathode and (c) the electroplated $\mathrm{Zn}$ anode after 450 charge/discharge cycles.
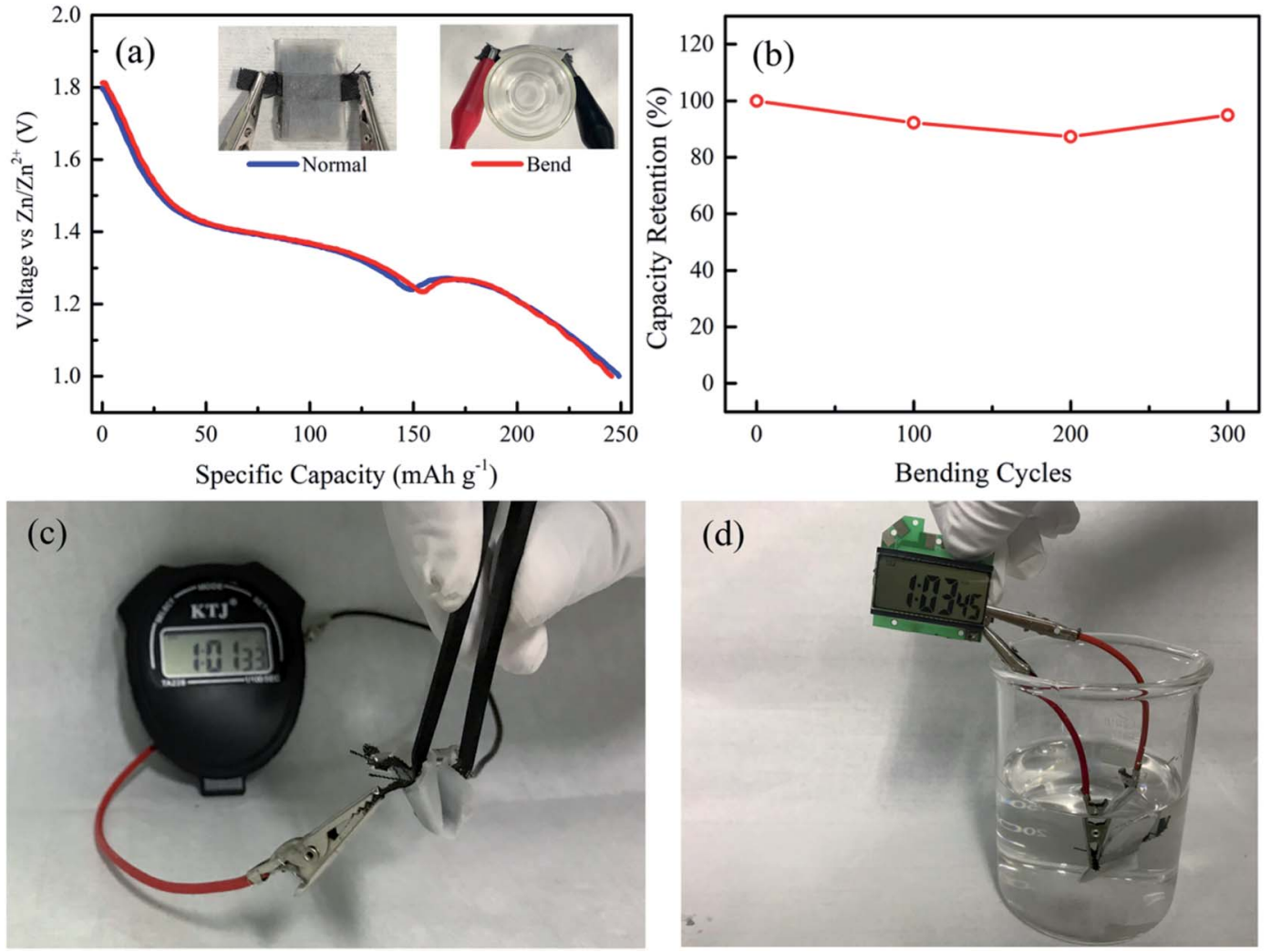

Fig. 4 (a) Discharge curves under normal and bending conditions. (b) The bending test of solid-state ZIBs with KCR electrolyte for 300 cycles. (c) A solid-state ZIB with KCR electrolyte powers a timer under 180 degrees of bending conditions. (d) A solid-state ZIB with KCR electrolyte powers a timer when the battery is fully immersed in the water. 
SEM image of Zn anode after 450 cycles (Fig. 3c). These results indicate that the morphology of cathode and anode materials remain almost unchanged as compared to the morphology of the pristine $\mathrm{MnO}_{2}$ and $\mathrm{Zn}$. The experimental results suggest utilization of KCR electrolyte maintains structural stability of $\mathrm{MnO}_{2}$ cathode and $\mathrm{Zn}$ anode, which improves the stability of the solid-state ZIBs. Fig. S6a $†$ further shows the SEM image of a fresh zinc foil, which has a very smooth surface. When utilized as an anode and cycled at $6.0 \mathrm{~A} \mathrm{~g}^{-1}$ for 100 cycles in the aqueous electrolyte, the surface of zinc foil becomes textured and zinc dendrite formation is observed (Fig. S6b $\dagger$ ). In contrast, the zinc foil after 100 cycles at $6.0 \mathrm{~A} \mathrm{~g}^{-1}$ in KCR electrolyte showed evener surface and no noticeable zinc dendrites are observed (Fig. S6c广). Based on the above results, it is found that the utilization of KCR electrolyte significantly inhibits the growth of $\mathrm{Zn}$ dendrites, which effectively reduce the chances of short circuit. The exceptional electrochemical performance indicates that the ZIBs with KCR electrolyte are promising as highperformance, long-life, low-cost and environmentally-friendly flexible energy storage devices.

Flexibility is essential for the application of solid-state ZIBs in wearable electronics. To test the flexibility of the solid-state ZIBs with KCR electrolyte, the fabricated devices were bended around a radius of $1.37 \mathrm{~cm}$. Experimental results show that the batteries still maintained the discharge profile and AC impedance spectra after test (Fig. $4 \mathrm{a}$ and $\mathrm{S} 7 \dagger$ ). The flexibility of the solid-state ZIBs with KCR electrolyte was further verified by continuously bending the battery by $180^{\circ}$. After 300 bending cycles, 95\% capacity was retained (Fig. 4b). These observations demonstrate a good mechanical stability of the KCR electrolyte. Moreover, the solid-state ZIBs with KCR electrolyte successfully powered a timer under bending condition, demonstrating its promising potential in personalized wearable electronics (Fig. 4c). This good flexibility is due to the excellent flexibility of the materials in the battery, including the KCR electrolyte and the carbon cloth current collector. The solid-state ZIBs also powered a timer when the entire device was immersed in water, demonstrating its good waterproofness (Fig. 4d).

\section{Conclusions}

In summary, we successfully prepare a non-toxic, high-ionic conductivity, low-cost and environmentally-friendly, flexible quasi-solid-state electrolyte for ZIBs application. The ZIBs with such electrolyte show a high specific capacity, fast charging and discharging capability, good cycling stability, and high reliability bearing cycles of bending. The utilization of KCR electrolyte maintains structural stability of cathode and anode after long cycling, which improves the stability of the solid-state ZIBs. With the excellent electrochemical performance and the ease of fabrication, such ZIBs with KCR electrolytes are very promising for use as wearable energy storage devices.

\section{Conflicts of interest}

There are no conflicts to declare.

\section{Acknowledgements}

This work is supported by the China Postdoctoral Science Foundation funded project (2017M620517). Yuan Huang and Zigang Li would like to acknowledge financial support from the Shenzhen Science and Technology Innovation Committee (No. JCYJ20170818090257257, and No. KQJSCX 20170728101942700).

\section{References}

1 M. Balogun, Y. Hao, L. Yang, W. Qiu, Y. Huang and Z. Liu, Energy Environ. Sci., 2018, 11, 1859-1869.

2 X. Huang, G. Diao, S. Li, M. Balogun, N. Li and Y. Huang, RSC Adv., 2018, 8, 17056-17059.

3 B. Long, L. Luo, H. Yang, M. Balogun, S. Song and Y. Tong, ChemistrySelect, 2018, 3, 6965-6971.

4 G. Diao, M.-S. Balogun, S.-Y. Tong, X. Guo, X. Huang, Y. Mao and Y. Tong, J. Mater. Chem. A, 2018, 6, 15274-15283.

5 Y. Fu, Q. Wei, G. Zhang, X. Wang, J. Zhang, Y. Hu, D. Wang, L. Zuin, T. Zhou, Y. Wu and S. Sun, Adv. Energy Mater., 2018, 8, 1801445.

6 J. Huang, Z. Wang, M. Hou, X. Dong, Y. Liu, Y. Wang and Y. Xia, Nat. Commun., 2018, 9, 2906.

7 D. Chao, C. Zhu, M. Song, P. Liang, X. Zhang, N. H. Tiep, H. Zhao, J. Wang, R. Wang, H. Zhang and H. J. Fan, Adv. Mater., 2018, 30, 1803181.

8 F. Mo, H. Li, Z. Pei, G. Liang, L. Ma, Q. Yang, D. Wang, Y. Huang and C. Zhi, Sci. Bull., 2018, 63, 1077-1086.

9 P. Hu, T. Zhu, X. Wang, X. Wei, M. Yan, J. Li, W. Luo, W. Yang, W. Zhang, L. Zhou, Z. Zhou and L. Mai, Nano Lett., 2018, 18, 1758-1763.

10 L. Kang, M. Cui, F. Jiang, Y. Gao, H. Luo, J. Liu, W. Liang and C. Zhi, Adv. Energy Mater., 2018, 8, 1801090.

11 K. Lu, B. Song, Y. Zhang, H. Ma and J. Zhang, J. Mater. Chem. A, 2017, 5, 23628-23633.

12 L. Ma, S. Chen, H. Li, Z. Ruan, Z. Tang, Z. Liu, Z. Wang, Y. Huang, Z. Pei, J. A. Zapiena and C. Zhi, Energy Environ. Sci., 2018, 11, 2521-2530.

13 S. Zhang, N. Yu, S. Zeng, S. Zhou, M. Chen, J. Di and Q. Li, J. Mater. Chem. A, 2018, 6, 12237-12243.

14 H. Pan, Y. Shao, P. Yan, Y. Cheng, K. S. Han, Z. Nie, C. Wang, J. Yang, X. Li, P. Bhattacharya, K. T. Mueller and J. Liu, Nat. Energy, 2016, 1, 16039.

15 Y. Zeng, X. Zhang, Y. Meng, M. Yu, J. Yi, Y. Wu, X. Lu and Y. Tong, Adv. Mater., 2017, 29, 1700274.

16 J. P. T. Guisao and A. J. F. Romero, Electrochim. Acta, 2015, 176, 1447-1453.

17 H. Li, C. Han, Y. Huang, Y. Huang, M. Zhu, Z. Pei, Q. Xue, Z. Wang, Z. Liu, Z. Tang, Y. Wang, F. Kang, B. Li and C. Zhi, Energy Environ. Sci., 2018, 11, 941-951.

18 N. K. Zainuddin and A. S. Samsudin, Mater. Today Commun., 2018, 14, 199-209.

19 P. C. Selvin, P. Perumal, S. Selvasekarapandian, S. Monisha, G. Boopathi and M. V. L. Chandra, Ionics, 2018, 24, 35353542 . 
20 S. Rudhziah, A. Ahmad, I. Ahmad and N. S. Mohamed, Electrochim. Acta, 2015, 175, 162-168.

21 I. J. Shamsudin, A. Ahmad, N. H. Hassan and H. Kaddami, Ionics, 2016, 22, 841-851.

22 S. Rudhziah, M. S. A. Rani, A. Ahmad, N. S. Mohamed and H. Kaddami, Ind. Crops Prod., 2015, 72, 133-141.

23 M. M. Pérez-Madrigal, F. Estrany, E. Armelin, D. D. Díaz and C. Alemán, J. Mater. Chem. A, 2016, 4, 1792-1805.

24 X. Hu, L. Fan, G. Qin, Z. Shen, J. Chen, M. Wang, J. Yang and Q. Chen, J. Power Sources, 2019, 414, 201-209.

25 T. M. D. Palma, F. Migliardini, D. Caputo and P. Corbo, Carbohydr. Polym., 2017, 157, 122-127.
26 Y. Huang, J. Liu, Q. Huang, Z. Zheng, P. Hiralal, F. Zheng, D. Ozgit, S. Su, S. Chen, P.-H. Tan, S. Zhang and H. Zhou, npj Flexible Electronics, 2018, 2, 21.

27 L. Fan, L. Wang, S. Gao, P. Wu, M. Li, W. Xie, S. Liu and W. Wang, Carbohydr. Polym., 2011, 86, 1167-1174.

28 W. Sun, F. Wang, S. Hou, C. Yang, X. Fan, Z. Ma, T. Gao, F. Han, R. Hu, M. Zhu and C. Wang, J. Am. Chem. Soc., 2017, 139, 9775-9778.

29 K. Wang, X. Zhang, J. Han, X. Zhang, X. Sun, C. Li, W. Liu, Q. Li and Y. Ma, ACS Appl. Mater. Interfaces, 2018, 10, 24573-24582. 